\title{
ЭВОЛЮЦИЯ КУЛЬТУРНОГО СМЫСЛА ЖЕРТВОПРИНОШЕНИЙ
}

\author{
А. А. Горелов
}

Институт философии РАН,

\section{Т. А. Горелова}

Московский гуманитарный университет

Аннотация: В работе рассматривается изменение смысла жертвоприношений в процессе эволюции духовной культуры.

Текст доклада авторов на Всероссийской научной конференции «Культура между Логосом и Мифом: к проблеме бессознательного (к 80-летию А.Э. Воскобойникова)», которая прошла в Московском гуманитарном университете 26-27 октября 2017 года.

Ключевые слова: жертва; жертвоприношение; эволюция; мистика; мифология; религия; наука; подмена; культурное разнообразие

\section{THE EVOLUTION OF THE CULTURAL MEANING OF SACRIFICE}

\author{
A. A. Gorelov \\ Institute of Philosophy, Russian Academy of Sciences, \\ T. A. Gorelova \\ Moscow University for the Humanities
}

Аннотация: The paper considers the change of the meaning of sacrifice in the process of spiritual culture evolution.

The text of the authors' speech at the All-Russian Scientific Conference "Culture between Logos and Myth: on the Issue of the Unconscious (dedicated to the 80th anniversary of A. E. Voskoboynikov)", which was held at Moscow University for the Humanities on 26-27 October 2017.

Ключевые слова: sacrifice; offering; evolution; mysticism; mythology; religion; science; substitution; cultural diversity

Жизнь прожить,

Идя навстречу ветрам,

Помогая, жертвуя, спасая,

Поневоле становясь бессмертным,

В памяти потомков воскресая.

А. Э. Воскобойников 
В материальном мире имеются четыре основные физические силы (биологи к ним прибавили жизненную силу, а психологи - волю). В мире духовной культуры выделяют три основные силы - веру, воображение, разум, которые вместе с пятью чувствами и интуицией создают культуру. Аналогично физической и психической энергии можно говорить о культурной (духовной) энергии. Одним из основных источников этой энергии является жертва. Как при смене общественно-экономических формаций только способ производства как форма не обладает сам по себе достаточной энергией, чтобы вытеснить другой, так и отрасль культуры как форма не обладает необходимой силой, чтобы сделать это, и нужна энергия, чтобы «процесс пошел». Жертвы нужны как топливо, создающее необходимый для победы заряд энергии. Из истории культуры можно констатировать, что именно жертва ведет к победе новой отрасли культуры. Смерть Сократа, Иисуса Христа, Джордано Бруно - это точки бифуркации в развитии культуры, которые привели к становлению соответственно философии, религии и науки.

Механизм действия жертвы аналогичен физическому процессу: гибель высвобождает большое количество энергии, которая подпитывает систему и приводит ее в состояние неустойчивости. Чем больше количество энергии, тем больше вероятность перехода системы в новое качество.

Эволюция культуры и трансформация смысла жертвоприношений параллельные процессы в истории. Жертвоприношение - обрядово-духовный $а к т$, с помощью которого жертвователь пытается воздействовать на божество, выражая покорность, благодарность, желание умилостивить и ожидая ответного дара не только в виде каких-либо материальных событий и явлений, но также в духовном очищении и искуплении грехов жертвователя. Иными словами, жертвоприношение включает материальный элемент - собственно жертву — и духовный элемент — различные проявления чувств и ожиданий. Модификация соотношений этих двух элементов выражает смысловую нагрузку жертвоприношения.

В первоначальном смысле жертвенный ритуал имеет мистическое значение: жертва устанавливает магическую связь между жертвователем и тем, кому она предназначается. Следовательно, мотив жертвоприношения подсознательно не бескорыстен, а скорее базируется на обмене: жертвователь просит даров и, чтобы получить их, подвергает себя определенным лишениям, самоограничению, т. е. жертвует чем-то. В соответствии с законом обмена: чем больший дар ожидает проситель, тем более высокую плату он должен внести за него, хотя содержание и размеры платы довольно субъективны и зависят от нормативов и установок исторически изменяющегося общества, а также от личных претензий просящего. Таким образом, у всех форм отречения и жертвования есть «вполне эгоцентрический смысл: под- 
Научные труды Московского гуманитарного университета 2018 № 2

вергая себя определенным физическим лишениям, Я (скорее «мы», имея в виду родовое коллективное сознание примитивных народов. $-A$. Г., Т. Г.) стремится тем самым одновременно усилить свою мана, свою физически-магическую власть и действенность» (Кассирер, 2001: 232). Несмотря на неравновесность этой духовной конструкции, в своей основе жертвенный ритуал - это прошение о милости, обращенное к высшей силе.

Сходство типов и форм основных жертвоприношений у различных древних племен и народов, отмеченное многими исследователями первобытных культур (Тайлор, 1989; Фрэзер, 1985 и др.), утверждает не только психологическое сходство людей разных рас и племен, но свидетельствует о параллелях эволюционного развития не связанных друг с другом древних культур. В жертвоприношениях отчетливо прослеживаются параллели в развитии различных человеческих сообществ, которые можно обнаружить в «удивительном изоморфизме культур Запада и Востока, конвертируемости имен и символов, относящихся к богам плодородия, грозы, войны и прочим. Непреходящее значение языческих архетипов сознания проявляется именно в том, что символизирует космос, природу» (Панарин, 2002: 116).

Первобытное мышление испытывало потребность постоянно существовать в полном и организованном мире, в Космосе. По мнению М. Элиаде, жертвоприношение выполняло роль священного ритуала овладения пространством, временем, природой, которые первоначально не воспринимались как свои и которые надо было освятить, чтобы создать «свой Мир» (Элиаде, 1994: 126).

На стадии мистики, которую можно определить как «нерациональное знание, основанное на интуиции и сопричастности с Универсумом» (Горелов, 2002: 31), в культурной жизни человека действовали законы, которые раскрываются современной экологией как принципы «все связано со всем» и «ничто не дается даром». Древний человек и шагу не мог ступить, не задобрив предварительно какое-либо сверхъестественное существо. Любое изменение направления жизни, любой переход должен был происходить по определенной схеме, в противном случае желаемый результат был недостижим (Элиаде, 1996: 230-233). Поэтому обряды составляли главный смысл ежедневных человеческих действий. Главной целью всех производимых обрядов и действий было объединение людей для того, чтобы преодолеть страх смерти. «Человек архаических обществ стремился победить смерть, придавая ей такое значение, что в конечном итоге, она перестала быть прекращением, а стала обрядом перехода» (там же: 264). Жертвоприношения потому и получили такое широкое распространение в древнем обществе, что реализовывали одновременно и ритуал защиты от страха смерти, и дар божествам, устанавливающий взаимодействие и единство с ними. 
Г. Спенсер назвал три эволюционных этапа жертвоприношений: первый этап - «кормление» покойников, второй - подношение духам и богам, третий - принесение в жертву себя. Он указывает параллели в генезисе приношения пищи мертвым и приношении пищи и питья божествам. «Как мотивы, так и способы совершения обоих действий одинаковы <...> В обоих случаях мы видим приношение еды, более крупные жертвоприношения в специальных случаях и более обширные ежегодные жертвоприношения. Предлагаемые предметы одни и те же - это быки, козы и т. п., хлеб, печенья, местные вина, благовония и цветы <...> Полагают, что боги пользуются жертвоприношениями таким же способом, как и тени умерших, и эти приношения им одинаково приятны» (Спенсер, 1997: 273). Генезис человеческих жертвоприношений (крови и частей тела) имеет такие же параллели с погребальными обрядами.

На следующем этапе эволюции культуры с рождением искусства, которое является «синтезом мистики и языка (в том числе языка пластики, живописи и иных форм), мышлением в образах» (Горелов, 2002: 51-52), возникают зрительные символические формы жертвенных обрядов. Пронзенные стрелами олени и лани с наскальных «холстов» - это животные, обреченные на жертву (поэтому на таких рисунках нет растений, а люди выписаны лишь схематично).

Выполняя свою функцию как синтез мистики и искусства, мифология была призвана объяснить наиболее важные события начала истории в целостных духовных произведениях. Миф образует мост между искусством, в основе которого лежат образы, и философией, в основе которой рациональное мышление. Именно со стадии мифологии начинается бурное развитие духовной культуры как «символической системы, которая есть третье звено между системой рецепторов и эффекторов <...> Человек живет отныне не только в физическом, но и символическом универсуме» (Кассирер, 1998: 470-471).

На стадии мифа жертвенные обряды расцветают. Мифология строит убедительные обоснования и систематизирует обряды. «Главная функция мифа заключается в “установлении” образцовых моделей всех обрядов и всех значимых человеческих деятельностей таких, как питание, половые отношения, работа, воспитание и т. п. Поступая как существо, взявшее на себя всю полноту ответственности, человек имитирует образцы деяния богов, повторяет их поступки ...» (Элиаде, 1994: 65). Образно говоря, миф стал не только родовой «идеологией» жертвоприношений и других обрядов, так как мифологические образы пронизывали сознание и подсознание каждого человека и всей культуры в целом, но также и их «теорией», потому что общность их проявлений в разных символах и культурах свидетельствует 
Научные труды Московского гуманитарного университета 2018 № 2

об объективности мифологической гносеологии. Совокупность всех мифов разных народов создает такое мировоззрение, которое М. Элиаде назвал «космической религией», представляющей «Космос в его полноте как реальный живой и священный организм» (там же: 75).

В мифологиях различных народов оформляется идея рождения мира в результате жертвы, причем речь идет о человеческом (божественном) акте самопожертвования, т. е. о космогоническом мифе Сотворения через предание смерти (или добровольную смерть) человека или бога. Таковы миф об Имире в германской мифологии, о Пуруше в индийской, о Пан-ку в китайской. «Согласно другой группе мифов, не только Космос, но и съедобные растения, человеческие расы и даже различные общественные классы зарождаются в результате принесения в жертву Первого существа, из его плоти» (там же: 42). Это первое убийство радикально изменило образ бытия человеческой расы. Идея жертвоприношения в процессе Сотворения мира была распространена на все созидательные действия племени. «Воспоминание, производимое в обрядах (путем повторения первичного убийства), играет решающую роль: люди должны остерегаться забвения того, что произошло in illo tempore (в те времена, т. е. в начале времен. - A. Г., Т. Г.)» (там же: 67).

Жертвоприношение осознается как способ возрождения жизни через смерть. «Смерть, сама по себе, не является определенным концом или абсолютным уничтожением, как иногда считается в современном мире. Смерть приравнивается к семени, которое засеивается в чрево Матери-Земли, чтобы дать рождение новому растению <...> Вот почему тела, захороненные в период неолита, находят лежащими в зародышевом положении <...> Люди в своей смерти и погребении были жертвоприношениями Земле. В конечном итоге, именно благодаря этому жертвоприношению может продолжаться жизнь, и люди надеются после смерти вернуться обратно к жизни. Пугающий аспект Матери-Земли как Богини Смерти объясняется космической неизбежностью жертвоприношения, которое лишь одно позволяет перейти от одной формы существования к другой, а также обеспечивает непрерывный круговорот Жизни» (Элиаде, 1996: 219-220). Жертва приобретает циклический характер: каждая прежняя жертва становится материалом для новой, и этот цикл нескончаем. Особое значение в этой связи приобретает антропофагия - человеческие жертвоприношения, которые по большей части связаны с земледелием. В процессе творения Мира появление растений связано с убийством. «Чтобы сохранился растительный мир, человек должен убить и быть убитым; он должен, кроме того, выполнять свою детородную функцию...» (Элиаде, 1994: 68). С точки зрения «примитивного» человека, ритуальное человекоубийство и каннибализм - это культовое поведение, основанное на религиозном видении жизни, которое 
ввели сверхъестественные Существа, чтобы позволить людям взять на себя ответственность за Космос. В этой ответственности не только за поддержание, но и за возрождение «моего Мира», Космоса, и заключался смысл жизни каждого человека как члена рода. С рождения он включался в смысложизненные процедуры и не выходил из них до последнего вздоха. Сама его смерть была началом кого-то другого. «Онтологическая жажда», по выражению М. Элиаде, является одновременно и религиозной потребностью, и утолением жажды смысла жизни. Смысл жизни проявлялся как врожденная способность архаического человека.

В мифологической культуре, как и ранее, в первобытной, жертва предстает как источник и двигатель жизни. По Элиаде, «человек архаических обществ стремился победить смерть, придавая ей такое значение, что, в конечном итоге, она перестала быть прекращением, а стала обрядом перехода. Другими словами, для примитивных народов человек умирает по отношению к чему-то, что не является существенным, человек умирает для мирской жизни» (Элиаде, 1996: 264).

В эпоху неолита с переходом от присваивающего хозяйства к производящему изменилась не только форма жертвоприношений - духам начинают посвящать живых животных, но и сам религиозный опыт, который становится более конкретным, тесно связанным с жизнью. Божества, заменившие у первобытных народов богов небесной структуры, были божествами плодородия, изобилия, полноты жизни, т. е. божествами, стимулирующими и наполняющими жизнь. «Открыв священность Жизни, человек все больше и больше оказывается в плену собственного открытия: он отдается во власть жизненных иерофаний (появление священного. - A. Г., Т. Г.) и отдаляется от священности, стоящей над его повседневными, непосредственными нуждами» (Элиаде, 1994: 82). Возникает состояние, которое М. Элиаде называет экономикой священного: чем ценнее жертва для человека, тем угоднее она богам.

Как обычно бывает после кульминации, происходит постепенный спад, а позже и подмена реальной жертвы символической. С позиции мирского в смысл жертвоприношения внутренне заложена подмена: жизнь рода «выкупалась» отдельными человеческими жизнями, будь то жизни сыновей-первенцев знатных родов в критические моменты войн, как, например, в Карфагене, Финикии и Древней Сирии (угодность жертвы определялась тяжестью потери), или как в Древней Греции, где в жертву приносились представители чужих народов - рабы и пленные. По степени «кровавости» жертвы можно разделить на следующие группы: жертвенные убийства людей (чаще всего детей и представителей других племен), убийство животных, жертвенный ритуал без убийства животного («козел отпущения»), 
Научные труды Московского гуманитарного университета 2018 № 2

бескровные жертвы (например, пожертвования мукой, маслом, вином, ладаном), символические жертвы (например, подмена обещанного Юпитеру скота таким же количество головок чеснока в Древнем Риме или использование в жертвенном ритуале животных, вырезанных из бумаги в Китае). В истории многих жертвенных ритуалов видно стремление к снижению «степени кровавости». Так, «у тлинкитов Северной Америки бытовал жестокий обычай: при постройке дома в ямы, вырытые под опорные столбы, бросали тело человека. Позже жертвоприношение приняло символическую форму: раба заставляли влезать в каждую из вырытых ям, а потом отпускали на волю. Дальнейшим смягчением кровавой строительной жертвы выглядит традиция ... класть под углы строящегося дома горсть зерна, клок шерсти, серебряную монету и т. п.» (Токарев, 1990: 598-599). Д. Фрэзер находит самое простое объяснение упрощения жертвоприношений в том, что «в обыденной житейской сутолоке, не терпящей утомительно-длинных ритуалов, народ сократил это всесильное, разработанное до мелочей средство <...> превратив его в простое и удобное орудие, которое в заурядных случаях можно легко и без всякой проволочки применить» (Фрэзер, 1985: 246). Автор очень точно замечает, что ритуал упрощается, когда из «всесильного средства» поддержания жизни он превращается в «заурядный случай», т. е. исчезают духовное упование, вера, энергия благоговения, сакральность, которые вкладывались в ритуал, а остается лишь материальная форма как последовательность действий. Тогда духовный акт жертвоприношения превращается в слепую традицию.

Переломным пунктом в истории жертвоприношений становится «осевое время», когда «для всех народов были найдены общие рамки понимания их исторической значимости <...> произошел самый резкий поворот в истории. Появился человек такого типа, какой сохранился и по сей день» (Ясперс, 1994: 32). Сразу в трех точках планеты - Древней Индии, Древнем Китае, Древней Греции - началась борьба рациональности и рационально проверенного опыта против мифа. Необходимость систематизации мифов формировала и оттачивала логику и правила понятийного мышления, которые, в свою очередь, привели к становлению философского мироощущения. Мифологическое время само породило основания, губительные для него. Начался процесс, который К. Ясперс назвал «освобождением от глухого самосознания и страха перед демонами» (там же: 33). Существование магических связей между людьми и богами было подвергнуто сомнению, и вера в могущество жертвоприношения слабела. «Космическая» религиозность утратила ясность и оптимизм. В «осевое время» рождается ощущение индивидуальности и личности, человек духовно отделяется от рода. Формирующиеся интеллектуальные элиты древних цивилизаций все бо- 
лее вырываются за границы устоявшейся религиозности. Так, в Древней Индии подверглась научному развитию концепция космических циклов, которая, лишившись первичного религиозного содержания, породила безысходность перед их бесконечным повторением. Единственной надеждой и уходом от пессимизма жизни стало невозвращение, устранение кармы и окончательный выход из колеса перевоплощений - нирвана. Точно также в Древней Греции в системах философов поздней античности - пифагорейцев, платоников, стоиков - возникла идея точной повторяемости циклов рождения и смертей Мира, воспроизводящих до бесконечности одни и те же ситуации. Историческое рождение личности сопровождалось утратой родового смысла жизни, отчаянием и пессимизмом. Последующая эволюция культуры - это есть расширение и обобщение символов от темных, насыщенных эмоциями символов мифа к ясным и рациональным символам философии и позже науки.

На последующих этапах развитии западной культуры система жертвоприношений как мировоззрение была разрушена, но как всегда бывает в культуре, она не исчезла полностью: материализованный ритуал был заменен духовным устремлением. На стадии расцвета философии интеллектуальные элиты древних индийцев, китайцев и греков преобразуют мифологические теологии в рационалистические философские системы. Греческая мифология - самая четкая, логичная, последовательная и яркая, и поэтому не случайно именно она прорвала собственные рамки и превратилась в новую отрасль культуры - философию. Психея была преобразована в понятие души, Афродита - в понятие любви, Солнце было объявлено мировым Разумом, а солнечные иерофании превратились в идеи. На этом пути к рационализму религиозность почти полностью разрушается. Начавшаяся десакрализация Космоса будет продолжена на последующих этапах развития европейской культуры.

На следующем этапе мировых религий христианство смогло внести глубокие коренные изменения в религиозные оценки Космоса и Жизни, но не отбросило их полностью. Из быта людей постепенно уходило регулярное традиционное жертвоприношение, но самодвижение культуры звало к $\partial y-$ ховной жертве. Так идея принесения в жертву других в христианстве была заменена идеей жертвенности, самопожертвования, служения. С воплощением Бога на земле в историю вновь вошло священное. «Христианство, таким образом, выливается не в какую-то философию, а в теологию истории, так как вмешательство Бога в Историю, и особенно Воплощение в историческую личность Иисуса Христа, имеет трансисторическую цель: спасение человечества» (Элиаде, 1994: 73). Личностная специфика религиозного переживания включает не только оптимистическое радостное принятие мира 
Научные труды Московского гуманитарного университета 2018 № 2

с верой, надеждой и любовью к Богу; но и примирение со страданиями и злом как форма жертвоприношения; и следующий отсюда аскетизм и самостоятельное принятие дополнительных жертв, которые становятся желанными (Джемс, 1998: 170-171). Становление и кризис христианства связаны с всплеском человеческих жертвоприношений: на первом этапе ими становились сами христиане, терзаемые в клетках львами, а на последнем - epeтики и ведьмы, сгоравшие на кострах инквизиции. Последующий кризис мира, по мнению К. Юнга, в значительной мере был следствием угасания религиозности и вызван тем фактом, что христианские символы и «мифы» больше не воспринимались всем человеческим существом, сократились до слов и жестов, лишенных жизни, закосневших, объясняющихся внешними обстоятельствами и поэтому не играющих никакой роли в глубинной жизни психики.

В процессе «воцарения» науки в Новое время произошла окончательная переоценка ценностей «космической» религии. Очень хорошим примером этого процесса является трансформация ценностей, приписываемых природе. Магически-религиозная связь с природой, присущая архаичному человеку, была заменена эстетическим или просто сентиментальным чувством, туризмом, гигиеническим купанием в море и т. п., в то время как созерцание природы сменилось наблюдением, экспериментом и расчетом. Нельзя сказать об ученых, что они «не любят природу», но в их «любви» нет больше ничего от духовной позиции человека архаических культур.

Процесс десакрализации отдельных сторон жизни человека является частью гигантского преобразования Мира, которое взвалили на себя индустриальные общества. Оно стало возможным в результате разрушения тайны священного Космоса под воздействием научных теорий, экономизации всех сторон жизни и т. п. Жертвоприношение как основной священный ритуал был «изгнан» из «сознания» культуры, но экзистенциальная потребность в жертве не исчезает: жертвоприношение ушло из мистерий, но осталось в культурной ауре и в «подсознании» культуры. В культурной традиции произошла отмена насильственной материальной жертвы и замена ее добровольной духовной жертвенностью.

Жертва как основной мистический атрибут обрядов освящения как бы врастает в структуру духовной культуры. Характер жертвы зависит от типа культуры. Так, в религиозном типе культуры человек жертвует всем ради Бога, в научном - ради знания, в идеологическом - ради интересов класса, нации. Во всех случаях жертва служит двигателем культуры. Она предпринимается не для того, чтобы что-то произошло, а сама есть событие, за которым следует желаемое. Жертвоприношение на всем протяжении ее развития остается главным мотивом искупления («рождения») и подмены 
(«смерти») различных отраслей культуры. Добровольная жертва, жертвенность в широком смысле слова, возвещает прорыв, рождение нового духовного пласта культуры, тогда как подмена, символизация и насильственность жертвоприношения означают угасание духовной энергии, кризис культуры и жажду новой жертвы.

Культура не может победить насилием, она побеждает посредством добровольной жертвы. Отсюда обоснование добродетели: истинный прогресс - прогресс культуры - идет через жертву, а для того, чтобы быть способным к жертве, надо обладать добродетелью. Святость жизни проверяется готовностью к жертве. Если человек рвется к власти и готов идти по трупам, лишь бы удержать ее, то такой человек от дьявола. Если человек ради своих убеждений готов пожертвовать собой и никогда не изменяет им под влиянием внешних обстоятельств - такой человек от Бога. Духовное значение жертв прозрели те, кто называл жертвующих собой святыми. Святой говорит: «Я разрушаю себя для того, чтобы мир жил. Я даю своей жертвой энергию миру».

В широком смысле, культурная жертва есть способ инициации культуры и ее вечного возрождения. Жертва - мутация, ведущая к эволюции. Через добровольную жертву созидается новый культурный код. Переломные моменты истории, когда рождаются новые мировоззрения и отрасли духовной культуры, - это точки бифуркации, когда в процессе самоорганизации культура как суперсистема переходит к более высокому структурному уровню организации. Энергию к такому переходу, как видно из истории, предоставляет добровольная культурная жертва: смерть Сократа в конечном счете приводит к утверждению философии, распятие Иисуса Христа к расцвету религии, сожжение Д. Бруно - к быстрому развитию науки.

Жертва - энтропийный процесс с точки зрения физики, но негэнтропийный с точки зрения культуры. Разрушение телесного ведет к развитию духовного. Жертва создает свободную духовную энергию в культурной системе, которая обеспечивает становление новой отрасли и новое качество культуры в целом. Энергия жизни создает культурный синтез, энергия смерти обеспечивает его победу. Приведя к торжеству данную отрасль культуры, энергия распространяется на ее последователей, а затем воздействует на широкие массы, делая рождающихся в духе людей, как говорили индийцы, «дваждырожденными».

Но вот данная отрасль культуры приходит к власти и жертвы перестают быть необходимыми. Наступает время построения того, за что отдана жизнь. Сократ пожертвовал собой, а Аристотель предпочел покинуть Афины. Христос был распят, а Петр трижды отрекся от него. Бруно сожгли, а Галилей отказался от своих убеждений. В период культурной революции пре- 
Научные труды Московского гуманитарного университета 2018 № 2

обладает борьба. Развитие требует жертв, и эти жертвы дает революция. Гонения на другие отрасли культуры ведут к уменьшению культурного разнообразия. На синтезирующем этапе развития культуры, который можно назвать «нормальным» (по аналогии с нормальным периодом развития науки, по Куну), разнообразие культурной системы начинает увеличиваться.

Синтез, в свою очередь, подрывает господство данной отрасли культуры и приближает точку бифуркации следующей культурной революции. Создателей новых отраслей культуры (Сократ, Христос) убивали, осуществлявших культурный синтез (Овидий, Данте) чаще изгоняли, но они не были лишены возможности выполнить свое предназначение, так как для синтеза требуется время.

Взаимодействие мира культуры со средой в чем-то аналогично экологическим взаимодействиям. По мнению К. Лоренца, культуру можно уподобить биологическому виду. В данном случае мы проводим аналогию между отраслью культуры и биологическим видом, тип культуры уподобляем экосистеме, а культурное окружение - природной среде. Развитие культурной системы аналогично развитию экосистемы. Оно также идет в направлении ослабления доминирования и конкуренции и роста разнообразия и информации. Стадия зрелости экосистемы соответствует стадии культурного синтеза, на которой истина уже не глаголет устами младенца, а включает в себя все больше духовных компонентов, пока, наконец, на вершине могущества, когда кажется, что культурная система может включить в себя все, она не распадается.

Продолжим аналогию между развитием культуры и сукцессией. Как в экосистеме вид создает условия, благоприятные для существования другого вида, давая ему дорогу (анаэробные бактерии, продуцируя кислород, создали кислородную атмосферу и условия для аэробной жизни), так в культуре одна отрасль создает учреждения, которые затем выступают против нее (созданные католическим духовенством университеты вскоре стали его противниками). В итоге имеем спираль развития: жертва $\rightarrow$ развитие данной отрасли культуры $\rightarrow$ ее доминирование $\rightarrow$ подмена $\rightarrow$ жертва. Каждая отрасль проходит свой цикл (аналог экологической сукцессии).

Жертва - революционный момент в развитии культуры, синтез момент «нормальный» (по аналогии с нормальной наукой Т. Куна). За ним следует подмена. «Существует земной закон, по которому с того момента, как прекращается всякое преследование и достигается всеобщее признание, начинается и разложение» (Е. И. Рерих, цит. по: Ключников, 1991: 143). За великими жертвами стоят великие подмены: за Сократом - Марк Аврелий, за Христом - римский папа Борджиа, за Руссо - Робеспьер и т. д. Таков ритм развития духовной культуры, которое необратимо, поскольку закон 
необратимости эволюции, сформулированный в палеонтологии, универсален, а, стало быть, приложим и к сфере культуры.

Подмены начинаются с момента достижения данной отраслью главенствующего положения (это свойственно, как считает П. А. Сорокин, и типам культур). Свидетельством начала подмены служит агрессивность. Какое искушение - господствуя, взяться за меч! Но «взявший меч от меча и погибнет». Добровольная жертва - наиболее эффективное средство утверждения идеи, убийство - начало ее подмены.

Став господствующей, отрасль поддается «соблазну физического насилия» (слова Тойнби о папстве) и тогда «остальные папские добродетели быстро превратились в пороки; замена духовного меча на материальный есть главная и роковая перемена, а все другие - лишь ее следствия» (Тойнби, 1991: 330). То же самое случилось ранее с философией, которую не мог спасти, а только погубить философ на троне Марк Аврелий, а позже с идеологией, которая доказала, что нельзя добиться духовных целей материальными средствами. Все это, по мнению А. Тойнби, следствия «принесения в жертву духа во имя меча земного». Тут мы имеем дело с обратной жертвой - не низшего, тела во имя высшего - духа, но духа во имя тела. В этом суть подмены - принесение в жертву духа. Подмена - жертва наоборот. Это возвращает к пониманию войны как жертвоприношения.

Становясь главенствующей, отрасль культуры привлекает к себе все больше сторонников из нетворческого большинства, не столько из-за своих идеалов, сколько из-за положения, славы и власти, которые она дает. И это увеличивает опасность предательства и извращения целей данной отрасли. Конец очевиден. Жертва, переходя в организацию, а затем институт приближает подмену, утверждал Ж.-П. Сартр в «Критике диалектического разума» (он использовал понятия «инертной практики», «отчуждения», «овеществления», «серийности», рассеяния» и т. д.), но истина как устремление человека к поиску всегда находится на стороне жертвы.

Общество не может уничтожить культуру, потому что развивается за ее счет, но оно пытается упростить ее для повышения эффективности управления. Здесь действует кибернетический закон необходимого разнообразия (в соответствии с которым разнообразие управляющей системы должно быть выше разнообразия управляемой системы), который составляет основу подмен. Прогресс человечества, за который ответственна духовная культура, сходит на нет и даже направляется в обратную сторону. Жизнь создает силу инерции, препятствующей движению. Материальное торжество данной культуры чревато ее гибелью. Как говорил А. Бергсон, инерция материи сопротивляется жизненному порыву, энергии жизненного импульса. 
Могут ли существовать подмены без жертв? Жертва является источником развития и дает энергию, которая движет мир, а подмены стремятся его остановить. Можно привести аналогию с физическим законом инерции, который обобщил на биосферу В. И. Вернадский. Жертвенность создает энергию, которую гасит инерция подмен.

Почему нужно много отраслей и типов культуры и не происходит полной замены старого новым? Действует закон культурного разнообразия, который также аналогичен основному закону экологии (разнообразие повышает устойчивость системы), как закон жертвы - модели происхождения материи, предложенной И. Пригожиным, а закон подмены - закону роста энтропии. Закон жертвы ответственен за становление нового, закон разнообразия - за сохранение старого, закон подмены - за смену отраслей. Если бы не было подмены, не было бы потребности в обновлении; если бы не было жертв, не утверждалось бы новое; если бы не было стремления к разнообразию, старое погибало бы.

Данный подход утверждает, что добровольная жертва имеет не менее фундаментальное онтологическое основание, чем насилие, и каждый вправе занять свое место на шкале от жертвы до подмены, от насилия до любви (имеется в виду любовь-агапэ, жертвенная любовь).

\section{СПИСОК ЛИТЕРАТУРЫ}

Горелов, А. А. (2002) Эволюция культуры и экология. М.: Изд-во ИФ РАН. 245 c.

Джемс, У. (1998) Многообразие религиозного опыта // Мистика. Религия. Наука. Классики мирового религиоведения. Антология / сост. и общ. ред. А. Н. Красникова М.: Канон+. 432 с. С. 148-173.

Кассирер, Э. (1998) Избранное. Опыт о человеке. М.: Гардарика. 784 с.

Кассирер, Э. (2001) Философия символических форм. Т. 1. М. ; СПб. : Университетская книга. 271 с.

Ключников, Н. И. (1991) Провозвестница эпохи огня. Новосибирск: Дет. лит. Сиб. Отд-ние. 148 с.

Панарин, А. С. (2002) Православная цивилизация в глобальном мире. М.: Алгоритм. 496 с.

Спенсер, Г. (1997) Синтетическая философия. Киев: Ника-центр. 512 с. Тайлор, Э. (1998) Первобытная культура. М.: Политиздат. 573 с.

Тойнби, А. (1991) Постижение истории. М. : Прогресс. 736 с.

Токарев, С. А. (1990) Ранние формы религии. М. : Политиздат. 622 с. Фрэзер, Д. Д. (1985) Фольклор в Ветхом завете. М. : Политиздат. 542 с. Элиаде, М. (1994) Священное и мирское. М. : Изд-во МГУ. 144 с. 
Элиаде, М. (1996) Мифы, сновидения, мистерии. M. : REFL-book K.: Baклер. 288 с.

Ясперс, К. (1994) Смысл и назначение истории. М. : Республика. 527 с.

Дата поступления: 12.12.2017 г.

Горелов Анатолий Алексеевич - доктор философских наук, ведущий научный сотрудник Института философии РАН. Адрес: 119842, Россия, г. Москва, ул. Волхонка, д. 14. Тел.: +7 (495) 697-91-28. Эл. адрес: evolepis@iph. ras.ru

Горелова Татьяна Анатольевна - доктор философских наук, профессор кафедры философии, культурологии и политологии Московского гуманитарного университета. Адрес: 111395, Россия, г. Москва, ул. Юности, д. 5 . Тел.: +7 (499) 374-55-11. Эл. адрес: fylosofy@mosgu.ru

Gorelov Anatoly Alekseevich, Doctor of Philosophy, Chief Research Fellow, Institute of Philosophy, Russian Academy of Sciences. Postal address: 14 Volkhonka St., 119842 Moscow, Russian Federation. Tel.: +7 (495) 697-91-28. E-mail: evolepis@iph.ras.ru

Gorelova Tatyana Anatolievna, Doctor of Philosophy, Professor, Department of Philosophy, Culturology and Politology, Moscow University for the Humanities. Postal address: 5, Yunosti St., Moscow, Russian Federation, 111395. Tel.: +7 (499) 374-55-11. E-mail: fylosofy@mosgu.ru

\section{Для цитирования:}

Горелов А. А., Горелова Т. А. Эволюция культурного смысла жертвоприношений [Электронный ресурс] // Научные труды Московского гуманитарного университета. 2018. №2. URL: http://journals.mosgu.ru/trudy/article/ view/695 (дата обращения: дд.мм.гг.). DOI: 10.17805/trudy.2018.2.8 